ARTIGOS

\section{INTERNATIONAL NEW VENTURE, BORN GLOBAL E GLOBAL STARTUP: ANÁLISE DE PRODUÇÕES CIENTÍFICAS SOBRE OS BRICS}

\author{
INTERNATIONAL NEW VENTURE, BORN GLOBAL \\ E GLOBAL STARTUP: ANALYSIS OF SCIENTIFIC \\ PRODUCTIONS ABOUT BRICS
}

\section{RESUMO}

O estudo de empresas, cujo processo de internacionalização ocorre de forma acelerada e imediatamente, ou em curto espaço de tempo, após a sua fundação, é crescente, com destaque para o recente aumento de empresas provenientes de países emergentes. A relevância econômica, social e política desses países, alinhada à crescente atenção de pesquisadores nas últimas décadas, levanta a pertinência do tema. Logo, o presente artigo tem como objetivo analisar a produção científica existente sobre born globals originárias de países emergentes, com enfoque nos países que compõem os BRICS (Brasil, Rússia, Índia, China e África do Sul). Trata-se de um estudo bibliográfico que se baseou em produções científicas da área, levantadas na base de dados do EBSCO e anais de eventos da Associação Nacional de Pós-graduação e Pesquisa em Administração (ANPAD). As análises apontam para a necessidade de aprofundamento teórico e empírico para o maior entendimento do fenômeno born global nos países emergentes.

Marcus Alexandre Yshikawa

Salusse

msalusse@gmail.com

Doutor em Administração.

Professor da Fundação Getúlio

Vargas (FGV/EAESP). São

Paulo - SP - BR.

Maria Inês Presrlak mariapresrlak@gmail.com Mestra em Administração. Fundação de Apoio ao Ensino, Extensão, Pesquisa e PósGraduação. Cascavel - PR - BR.

Gustavo Yuho Endo gustavo_endo@yahoo.com.br Mestre em Administração. Professor na Universidade do Oeste Paulista. Presidente Prudente - SP - BR.
Palavras-chave: International New Venture. Born Global. Startup.

\begin{abstract}
The study of companies whose internationalization process occurs rapidly and immediately, or in a short time, after its foundation, is growing, with emphasis on the recent increase of companies from emerging countries. The economic, social and political relevance of these countries, aligned with the growing attention of researchers in recent decades, raises the relevance of the topic. Therefore, this article aims to analyze the existing scientific production on born globals from emerging countries, focusing on the countries that make up the BRICS (Brazil, Russia, India, China and South Africa). This is a bibliographic study based on scientific productions in the area, collected from the EBSCO database and annals
\end{abstract}


of events organized by the National Association of Postgraduate Studies and Research in Administration (ANPAD). The analyzes point to the need for further theoretical and empirical study for a better understanding of the born global phenomenon in emerging countries.

Keywords: International New Venture. Born Global. Startup.

\section{INTRODUÇÃO}

$\mathrm{Na}$ última década, observou-se a consolidação da importância do estudo sobre as international new ventures no âmbito da literatura sobre empreendedorismo internacional (KNIGHT; LIESCH, 2016; MCDOUGALL; OVIATT; SHRADER, 2003; MADSEN; SERVAIS, 1997). O fenômeno denominado international new ventures, born globals ou global startups surgiu em meados dos anos de 1980 (OVIATT; MCDOUGALL, 1994) e trouxe à literatura tradicional sobre internacionalização de empresas importantes desafios, ao identificar o fenômeno relacionado à internacionalização de pequenas e médias empresas ocorrida desde sua fundação ou em curto espaço de tempo após sua origem (KNIGHT; CAVUSGIL, 2004). Em um estudo que propõe uma agenda de pesquisa na área de negócios internacionais, Griffith, Cavusgil e Xu (2008) apontam para a necessidade de aprofundamento teórico sobre companhias born globals e empreendedorismo internacional, com destaque para fatores que determinam seu sucesso e sua evolução.

Destaca-se, nesse sentido, o questionamento da teoria desenvolvida pela escola nórdica de Uppsala baseada na lógica evolucionária do processo de internacionalização das empresas (JOHANSON; VAHLNE, 1990). Isso porque, em que pese existirem empresas que se internacionalizam por meio de um processo gradual, lento e após consolidação de suas atividades no mercado doméstico, a história recente tem observado uma quantidade cada vez maior de empresas cujo processo de internacionalização ocorre de forma acelerada e imedia- tamente ou em curto espaço de tempo, após a sua fundação.

O conceito de international new venture, utilizado neste estudo como sinônimo para born globals ou startup globais, refere-se a organizações que, desde o início, por meio do uso de recursos e venda de outputs, vislumbram a obtenção de vantagem competitiva (OVIATT; MCDOUGALL, 1994). Global startups, por sua vez, são definidas como a "manifestação mais radical de international new ventures, porque deriva de vantagem competitiva significativa da coordenação extensiva entre atividades organizacionais múltiplas." (OVAITT, MCDOUGALL, 1994, p. 59). No que tange ao conceito de born globals, o presente estudo segue a definição de Knight e Cavusgil (2004) que conceitua o termo como organizações de negócios que buscam, desde a sua criação, performance internacional superior por meio da aplicação de recursos baseados em conhecimento para a venda em vários países. Oviatt e McDougall (1994) destacam, ainda, que uma das características que distinguem essas startups é o fato de estas terem origem internacional, com comprometimento de recursos internacionais, bem como estratégia proativa e deliberada.

O surgimento da teoria sobre born globals possui origem norte americana e europeia, ou seja, em mercados maduros e com características distintas dos países emergentes, que possuem condições específicas que afetam a internacionalização das empresas que deles se originam. Utilizando-se dos critérios de classificação propostos por Ghemawat (2001), que estabelece quatro tipos de condições macro relacionadas aos países de origem - social, político-regulatório, geográfico e econômico - Cuervo-Cazura (2012) desenvolve argumentos no sentido de que diferenças existentes nos países emergentes afetam o processo de internacionalização das empresas oriundas desses contextos, com consequências significativas para seus respectivos processos de internacionalização.

É nesse contexto que o presente artigo se insere, abordando a seguinte problemática: como ocorrem as publicações sobre internatio- 
nal new venture, born global e global startups de 2003 a 2020 originárias de países emergentes com foco nos países que compõem os BRICS (Brasil, Rússia, Índia, China e África do Sul)?

Tal enfoque tem sua pertinência diante da relevância econômica, social e política dos países emergentes (VIJAYAKUMAR; SRIDHARAN; RAO, 2010), alinhada à crescente atenção dos pesquisadores com estudos sobre o tema, especialmente nas últimas três décadas, (THOMAS; MUELLER, 2000; ARDICHVILI; GASPARISHVILI, 2003; PAUL; ROSADO-SERRANO, 2019). O artigo de Wood et al. (2011) consiste em um dos únicos encontrados nessa pesquisa e que faz uso de dados coletados em importantes mercados emergentes do mundo, provenientes da Ásia (China e Índia), da África (África do Sul) e da América Latina (México). Verifica-se, no entanto, que, em se tratando de países emergentes, certamente o grupo de países de maior destaque é o grupo denominado BRICS, foco da presente análise.

Desse modo, o objetivo deste trabalho é analisar a produção científica existente sobre international new venture, born globals e global startups de países emergentes com enfoque nos BRICS (Brasil, Rússia, Índia, China e África do Sul). Para tanto, inicialmente, é apresentada a metodologia utilizada para a seleção dos artigos e a forma como a análise comparativa foi estruturada. Em seguida, os artigos são descritos e caracterizados em função de seus principais elementos constitutivos por meio do mapeamento das pesquisas encontradas. Por fim, são apresentadas as conclusões da análise comparativa e propostas sobre caminhos futuros a serem trilhados para o amadurecimento e desenvolvimento da teoria sobre born globals de países emergentes.

\section{METODOLOGIA}

Com o objetivo de identificar os estudos recentes publicados em periódicos científicos sobre international new ventures, born globals e global startups provenientes de economias emergentes, leia-se BRICS, este estudo possui abordagem qualitativa, descritiva e bibliográfica (CRESWELL, 2010; MARCONI; LAKATOS, 2010).

Trata-se, assim, de uma revisão sistemática de literatura que se caracteriza como tal dada a sequência de etapas pré-definidas (EVANS; PEARSON, 2001), bem como a geração de conhecimento por meio de tal levantamento (MENDES; FRACOLLI, 2008).

O presente estudo fez uso da base de dados da EBSCO-host e anais de eventos da Associação Nacional de Pós-graduação e Pesquisa em Administração (ANPAD), para o levantamento dos artigos, utilizando-se os termos relacionados ao fenômeno de interesse: "international new venture", "born global" e "global startup", bem como "BRICS". O período pesquisado foi de 2003 a 2020. O motivo da escolha do ano inicial reside no fato de ter sido nesse período que houve o surgimento dos estudos mais proeminentes sobre born globals em países emergentes.

Com base nos argumentos apresentados, um processo objetivo de seleção com fundamento em cinco critérios foi seguido com vista a conferir maior rigor metodológico à pesquisa realizada. Para que pudesse fazer parte da análise ora empreendida, o artigo deveria, assim: (i) ter sido publicado em um periódico acadêmico ou em congresso acadêmico entre 2003 e 2020; (ii) ser um artigo científico teórico ou empírico; (iii) ter sido escrito em inglês ou português, para que sua compreensão não sofresse viés de interpretação; (iv) ser relacionado diretamente ao tema de interesse; (v) ser relacionado diretamente aos países emergentes denominados BRICS.

Logo, a busca foi realizada em etapas, utilizando os termos individualmente "international new venture", "born global" e "global startup" e, na sequência, o uso da lógica booleana com a condição AND para "BRICS" em cada termo, além dos filtros acima citados.

A figura 1 resume a sistemática da presente revisão bibliográfica sistemática, com vista a melhor visualização das etapas seguidas no estudo. 
Figura 1 - Etapas da revisão bibliográfica sistemática

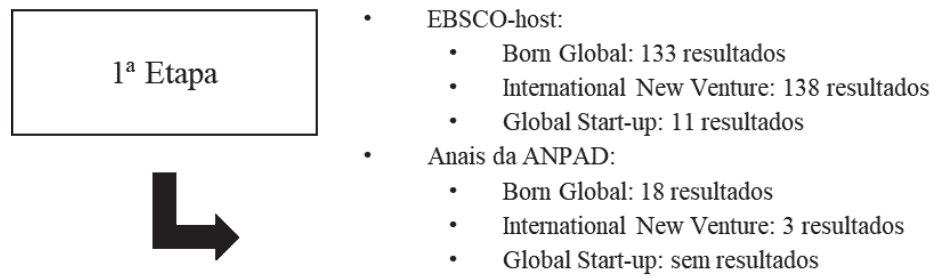

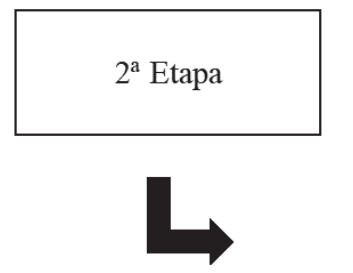

Condição AND BRICS para os termos na EBSCO-host:

- Born Global: 6 resultados válidos

- International New Venture: 4 resultados válidos

- Global Start-up: sem resultados válidos

Seleção dos artigos sobre BRICS nos anais da ANPAD:

- Born Global: 12 resultados válidos

- International New Venture: 1 resultado válido

- Global Start-up: sem resultados válidos

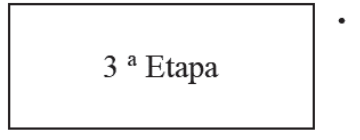

Fonte: elaborado pelos autores.

A busca por "born global" gerou 133 resultados; destes, apenas seis artigos válidos relacionados ao estudo de born globals de países emergentes, sendo dois da Índia, três do Brasil e um da China. O termo "international new venture" resultou em 138 artigos científicos, dentre eles, quatro artigos válidos. Por fim, com relação a "global startups", a pesquisa retornou 11 resultados de artigos, dos quais apenas 1 da Índia, no entanto, não adequado ao estudo em questão por não tratar especificamente do tema.

$\mathrm{O}$ artigo também procurou fazer o levantamento nos anais de eventos da Associação Nacional de Pós-graduação e Pesquisa em Administração (ANPAD), obtendo resultados apenas sob os temas "international new venture" e "born global"; assim, foram identificados 18 resultados para "born global" e 3 resultados para "international new venture" (dois descartados diante do foco do estudo), retornando 13 artigos válidos.

Após uma primeira análise dos títulos para se identificar, de forma genérica, os temas tratados pelos artigos, foi realizada a leitura dos abstracts dos artigos retornados nas pesquisas para validação da especificidade dos
Análise de títulos e resumos/abstracts, exclusão de artigos duplicados:

- EBSCO-host: 11 resultados válidos

- Anais da ANPAD: 12 resultados válidos assuntos tratados, bem como exclusão de artigos duplicados pela repetição dos termos "born global", "international new venture" e "global startup". Após o processo de seleção dos artigos, a pesquisa resultou em 24 artigos, sendo 11 provenientes da EBSCO-host e 12 dos anais da ANPAD.

Com base nesse levantamento, nas seções seguintes, são apresentadas as análises descritiva e de conteúdo dos 23 artigos selecionados.

\section{ANÁLISE DESCRITIVA DOS ARTIGOS}

Para facilitar a visualização das informações e obter uma visão geral dos artigos pesquisados, os presentes autores elaboraram duas tabelas que permitem melhor compreensão sobre os estudos. A tabela 1 traz os artigos publicados em periódicos. 
Tabela 1 - Visão geral dos artigos de periódicos sobre born globals, international new ventures e global startups nos BRICS

\begin{tabular}{|c|c|c|c|c|c|c|}
\hline Autor(es) & Periódico & País & $\begin{array}{c}\text { Pergunta de } \\
\text { pesquisa }\end{array}$ & Tipo & Base Teórica & Contribuição \\
\hline $\begin{array}{l}\text { Dib, Rocha e } \\
\text { Silva (2010) }\end{array}$ & $\begin{array}{c}\text { Journal of } \\
\text { International } \\
\text { Entrepreneurship }\end{array}$ & Brasil & $\begin{array}{l}\text { Desenvolver um } \\
\text { modelo integrativo } \\
\text { da literatura sobre } \\
\text { firmas e variáveis } \\
\text { empreendedoras, } \\
\text { comparando } \\
\text { born global e } \\
\text { tradicionais; testar } \\
\text { o modelo em } \\
\text { empresa brasileiras } \\
\text { de software } \\
\text { para explicar o } \\
\text { fenômeno em } \\
\text { uma economia } \\
\text { emergente }\end{array}$ & $\begin{array}{c}\text { Survey, } \\
\text { com firmas } \\
\text { brasileiras de } \\
\text { desenvolvimento } \\
\text { de software }\end{array}$ & Born Global & $\begin{array}{l}\text { Apresentação } \\
\text { de modelo } \\
\text { integrativo de } \\
\text { firmas e variáveis } \\
\text { empreendedoras }\end{array}$ \\
\hline $\begin{array}{c}\text { Clercq e } \\
\text { Zhou (2014) }\end{array}$ & $\begin{array}{c}\text { Journal of } \\
\text { International } \\
\text { Marketing }\end{array}$ & China & $\begin{array}{c}\text { Analisar por } \\
\text { que alguns } \\
\text { empreendimentos } \\
\text { são mais propensos } \\
\text { do que outros a } \\
\text { alocar esforços } \\
\text { significativos para } \\
\text { desenvolver novos } \\
\text { conhecimentos } \\
\text { sobre os mercados } \\
\text { estrangeiros e } \\
\text { quais são os } \\
\text { resultados desses } \\
\text { esforços; e } \\
\text { investigar como } \\
\text { as contingências } \\
\text { externas e } \\
\text { internas podem } \\
\text { moderar esse } \\
\text { efeito mediador } \\
\text { do esforço de } \\
\text { aprendizado } \\
\text { internacional. }\end{array}$ & $\begin{array}{c}\text { Survey com } \\
\text { empresas da } \\
\text { região costeiras } \\
\text { do sudeste da } \\
\text { China } \\
\text { (Províncias } \\
\text { de Zhejiang } \\
\text { e Fujian) por } \\
\text { meio de uma } \\
\text { base de dados da } \\
\text { Administração } \\
\text { Provincial para } \\
\text { Indústria e } \\
\text { Comércio. } \\
\text { Amostra de } 158 \\
\text { empresas. }\end{array}$ & $\begin{array}{l}\text { Postura Estratégica } \\
\text { Empresarial, } \\
\text { Desempenho } \\
\text { em mercados } \\
\text { estrangeiros }\end{array}$ & $\begin{array}{c}\text { Relação entre } \\
\text { postura estratégica } \\
\text { empresarial e } \\
\text { desempenho } \\
\text { internacional } \\
\text { por meio da } \\
\text { intensidade } \\
\text { dos esforços de } \\
\text { aprendizado gastos } \\
\text { nos mercados } \\
\text { estrangeiros. } \\
\text { Revelação de um } \\
\text { mecanismo de } \\
\text { comportamento } \\
\text { crítico que sustenta } \\
\text { as vantagens de } \\
\text { aprendizagem } \\
\text { desses } \\
\text { empreendimentos. }\end{array}$ \\
\hline $\begin{array}{l}\text { Fernandes, } \\
\text { Rocha e } \\
\text { Seifert } \\
\text { Junior } \\
(2011)\end{array}$ & $\begin{array}{l}\text { Entrepreneurship } \\
\text { Theory and } \\
\text { Practice }\end{array}$ & Brasil & $\begin{array}{l}\text { Analisar como } \\
\text { posicionar o } \\
\text { novo produto no } \\
\text { mercado norte } \\
\text { Americano e } \\
\text { quais estratégias } \\
\text { empresariais e de } \\
\text { marketing adotar, } \\
\text { considerando-se } \\
\text { a limitação de } \\
\text { recursos da firma. }\end{array}$ & $\begin{array}{l}\text { Estudo de caso } \\
\text { único }\end{array}$ & $\begin{array}{l}\text { Visão Baseada em } \\
\text { Recursos }\end{array}$ & $\begin{array}{c}\text { Identificação } \\
\text { de estratégias } \\
\text { de nicho para } \\
\text { penetração em } \\
\text { outros mercados. }\end{array}$ \\
\hline $\begin{array}{l}\text { Khavul et al. } \\
\text { (2010). }\end{array}$ & $\begin{array}{c}\text { Journal of } \\
\text { International } \\
\text { Marketing }\end{array}$ & China e India & $\begin{array}{l}\text { Analisar como } \\
\text { empresas } \\
\text { empreendedoras } \\
\text { inovadoras } \\
\text { de economias } \\
\text { emergentes } \\
\text { competem no } \\
\text { Mercado global }\end{array}$ & $\begin{array}{l}\text { Estudo empírico } \\
\text { (survey) } \\
\text { realizado com } \\
\text { aplicação } \\
\text { face-a-face de } \\
\text { questionário em } \\
\text { uma amostra de } \\
173 \text { empresas } \\
\text { nascentes, sendo: } \\
\text { China (90) } \\
\text { Índia (73) }\end{array}$ & $\begin{array}{c}\text { International } \\
\text { new ventures, } \\
\text { Capacidades } \\
\text { dinâmicas }\end{array}$ & $\begin{array}{c}\text { Forma de } \\
\text { competição } \\
\text { de empresas } \\
\text { empreendedoras } \\
\text { de economias } \\
\text { emergentes }\end{array}$ \\
\hline
\end{tabular}




\begin{tabular}{|c|c|c|c|c|c|c|}
\hline $\begin{array}{l}\text { Kumar } \\
(2012)\end{array}$ & $\begin{array}{c}\text { Journal of } \\
\text { International } \\
\text { Entrepreneurship }\end{array}$ & Índia & $\begin{array}{l}\text { Explorar como } \\
\text { as firmas que } \\
\text { começam a } \\
\text { internacionalizar } \\
\text { cedo combinam } \\
\text { diferentes recursos } \\
\text { para descobrir } \\
\text { oportunidades } \\
\text { no mercado } \\
\text { internacional }\end{array}$ & $\begin{array}{l}\text { Estudo de caso } \\
\text { com } 5 \text { firmas } \\
\text { indianas de TI }\end{array}$ & $\begin{array}{l}\text { Visão Baseada em } \\
\text { Recursos }\end{array}$ & $\begin{array}{c}\text { Análise de } \\
\text { recursos para } \\
\text { aproveitamento } \\
\text { de oportunidades } \\
\text { internacionais }\end{array}$ \\
\hline $\begin{array}{l}\text { Lamotte } \\
\text { e Colovic } \\
(2015)\end{array}$ & M@n@gement & Rússia & $\begin{array}{l}\text { Quais fatores } \\
\text { influenciam a } \\
\text { internacionalização } \\
\text { precoce de novos } \\
\text { empreendimentos } \\
\text { nas economias } \\
\text { emergentes? }\end{array}$ & $\begin{array}{c}\text { Análise com base } \\
\text { nas informações } \\
\text { contidas no } \\
\text { Business } \\
\text { Environment } \\
\text { and Enterprise } \\
\text { Performance } \\
\text { Survey } \\
\text { (BEEPS) de } \\
6153 \text { empresas } \\
\text { em } 2002,7699 \\
\text { empresas em } \\
2005,1952 \\
\text { empresas em } \\
2007 \text { e } 7773 \\
\text { empresas em } \\
2009\end{array}$ & $\begin{array}{c}\text { Internacionalização, } \\
\text { International new } \\
\text { ventures, Born } \\
\text { Global }\end{array}$ & $\begin{array}{c}\text { Compreensão } \\
\text { dos fatores que } \\
\text { influenciam a } \\
\text { internacionalização } \\
\text { precoce e das } \\
\text { especificidades da } \\
\text { internacionalização } \\
\text { de empresas } \\
\text { em economias } \\
\text { emergentes. }\end{array}$ \\
\hline $\begin{array}{l}\text { Naudé e } \\
\text { Rossouw } \\
(2010)\end{array}$ & $\begin{array}{c}\text { Journal of } \\
\text { International } \\
\text { Entrepreneurship }\end{array}$ & China & $\begin{array}{l}\text { Analisar em que } \\
\text { medida novas } \\
\text { firmas do setor } \\
\text { privado na China } \\
\text { internacionalizam; } \\
\text { identificar } \\
\text { os principais } \\
\text { determinantes da } \\
\text { internacionalização } \\
\text { precoce }\end{array}$ & $\begin{array}{c}\text { Análise feita } \\
\text { com base } \\
\text { em dados } \\
\text { secundários de } \\
3.948 \text { empresas } \\
\text { privadas } \\
\text { chinesas } \\
\text { respondentes } \\
\text { do World Bank } \\
\text { Investment } \\
\text { Climate Private } \\
\text { Enterprise } \\
\text { Survey em 2002 } \\
\text { e 2003. }\end{array}$ & $\begin{array}{l}\text { Empreendedorismo } \\
\text { Internacional; } \\
\text { Visão Baseada em } \\
\text { Recursos }\end{array}$ & $\begin{array}{l}\text { Motivações para } \\
\text { internacionalização }\end{array}$ \\
\hline $\begin{array}{c}\text { Ribeiro, } \\
\text { Oliveira } \\
\text { Junior e } \\
\text { Borini } \\
(2012)\end{array}$ & $\begin{array}{c}\text { Revista de } \\
\text { Administração } \\
\text { Contemporânea }\end{array}$ & Brasil & $\begin{array}{c}\text { Analisar como a } \\
\text { internacionalização } \\
\text { acelerada } \\
\text { de EBT está } \\
\text { associada aos } \\
\text { fatores do } \\
\text { ambiente externo } \\
\text { da empresa no país } \\
\text { de origem, aos } \\
\text { fatores } \\
\text { internos da } \\
\text { organização e aos } \\
\text { fatores ligados ao } \\
\text { empreendedor }\end{array}$ & $\begin{array}{c}\text { Survey, com } \\
\text { EBTs de } \\
\text { pequeno e médio } \\
\text { Porte }\end{array}$ & $\begin{array}{c}\text { Born Global, } \\
\text { Empresa de Base } \\
\text { Tecnológica (EBT) }\end{array}$ & $\begin{array}{c}\text { Relação entre } \\
\text { born global, } \\
\text { fatores externos no } \\
\text { país de origem e } \\
\text { fatores ligados ao } \\
\text { empreendedor }\end{array}$ \\
\hline
\end{tabular}




\begin{tabular}{|c|c|c|c|c|c|c|}
\hline $\begin{array}{l}\text { Varma } \\
(2010)\end{array}$ & $\begin{array}{c}\text { Advanced } \\
\text { Research in } \\
\text { Management }\end{array}$ & Índia & $\begin{array}{c}\text { Examinar a } \\
\text { emergência das } \\
\text { firmas Born } \\
\text { global no contexto } \\
\text { indiano, com foco } \\
\text { nas empresas que } \\
\text { fizeram aquisição } \\
\text { Born Global } \\
\text { Acquires (BGA) }\end{array}$ & $\begin{array}{c}\text { Estudo } \\
\text { documental } \\
\text { (dados } \\
\text { secundários de } \\
\text { empresas de } \\
\text { consultoria e } \\
\text { do centro de } \\
\text { monitoramento } \\
\text { da economia } \\
\text { indiana) na } \\
\text { indústria de TI } \\
\text { indiana. Estudo } \\
\text { de caso com } 5 \\
\text { firmas BGA. }\end{array}$ & $\begin{array}{l}\text { Visão Baseada em } \\
\text { Recursos, Teoria } \\
\text { Institucional }\end{array}$ & $\begin{array}{l}\text { Exame de Born } \\
\text { Global Acquires }\end{array}$ \\
\hline $\begin{array}{l}\text { Wood et al. } \\
\text { (2011) }\end{array}$ & $\begin{array}{l}\text { Journal of Small } \\
\text { Business Man- } \\
\text { agement }\end{array}$ & $\begin{array}{l}\text { China, Índia, } \\
\text { África do Sul e } \\
\text { México }\end{array}$ & $\begin{array}{c}\text { Entender por que } \\
\text { strategic early } \\
\text { internationalizers } \\
\text { de países } \\
\text { emergentes } \\
\text { perseguem } \\
\text { uma estratégia } \\
\text { altamente } \\
\text { arriscada de se } \\
\text { internacionalizar } \\
\text { cedo em seu } \\
\text { ciclo de vida } \\
\text { e como essa } \\
\text { internacionalização } \\
\text { cedo afeta a } \\
\text { habilidade } \\
\text { de competir } \\
\text { internacionalmente } \\
\text { quando comparada } \\
\text { a empresas que se } \\
\text { internacionalizam } \\
\text { tardiamente ou } \\
\text { sem intenção }\end{array}$ & $\begin{array}{l}\text { Estudo empírico } \\
\text { Entrevistas } \\
\text { face a face e } \\
\text { survey aplicadas } \\
\text { pessoalmente } \\
\text { e analisadas } \\
\text { utilizando-se o } \\
\text { STATA } 10.0 \text { em } \\
\text { uma amostra de } \\
257 \text { firmas } \\
\text { China (83) } \\
\text { Índia (79) } \\
\text { África do sul } \\
(55) \\
\text { México (40) }\end{array}$ & $\begin{array}{l}\text { Teoria Institucional, } \\
\text { Legitimidade } \\
\text { organizacional, } \\
\text { Visão Baseada em } \\
\text { Recursos }\end{array}$ & $\begin{array}{l}\text { Desenvolvimento } \\
\text { de tipologia de } \\
\text { international new } \\
\text { ventures moderado } \\
\text { por intenção } \\
\text { estratégica e } \\
\text { tempo para } \\
\text { internacionalização }\end{array}$ \\
\hline $\begin{array}{c}\text { Zhang, } \\
\text { Tansuhaj e } \\
\text { McCullough } \\
\text { (2009) }\end{array}$ & $\begin{array}{c}\text { Journal of } \\
\text { International } \\
\text { Entrepreneurship }\end{array}$ & China & $\begin{array}{c}\text { Desenvolver } \\
\text { uma escala de } \\
\text { capacidade de } \\
\text { empreendedorismo } \\
\text { internacional; } \\
\text { comparar a } \\
\text { capacidade em } \\
\text { firmas born globals } \\
\text { e exportadoras } \\
\text { tradicionais; } \\
\text { testar a relação } \\
\text { entre capacidade } \\
\text { empreendedora } \\
\text { internacional e } \\
\text { performance da } \\
\text { firma no mercado } \\
\text { internacional }\end{array}$ & $\begin{array}{l}\text { Survey, com } \\
\text { firmas de } \\
\text { manufatura } \\
\text { com vendas } \\
\text { no exterior } \\
\text { localizadas no } \\
\text { Oeste da China, } \\
\text { especificamente } \\
\text { na província } \\
\text { de Sichuan ou } \\
\text { próximas a ela }\end{array}$ & $\begin{array}{l}\text { Visão Baseada em } \\
\text { Recursos }\end{array}$ & $\begin{array}{l}\text { Contribuição } \\
\text { empírica sobre } \\
\text { capacidade } \\
\text { empreendedora }\end{array}$ \\
\hline
\end{tabular}

Fonte: elaborado pelos autores com base nos artigos analisados.

Na sequência, a tabela 2 apresenta os artigos selecionados nos anais da Associação Nacional de Pós-graduação e Pesquisa em Administração (ANPAD). 
Tabela 2 - Visão geral dos artigos publicados nos anais da ANPAD sobre born globals, international new ventures e global startups nos BRICS

\begin{tabular}{|c|c|c|c|c|c|}
\hline Autor(es) & País & Pergunta de pesquisa & Tipo & Base Teórica & Contribuição \\
\hline $\begin{array}{l}\text { Carvalho } \\
\text { e Paes } \\
(2006)\end{array}$ & Brasil & $\begin{array}{c}\text { Analisar em que } \\
\text { medida os principais } \\
\text { drivers associados } \\
\text { ao padrão vigente de } \\
\text { internacionalização de } \\
\text { empresas nascidas globais } \\
\text { vigoram também no caso } \\
\text { de um país considerado } \\
\text { emergente? }\end{array}$ & $\begin{array}{l}\text { Qualitativo, do tipo } \\
\text { estudo de caso, numa } \\
\text { empresa especializada } \\
\text { no licenciamento de } \\
\text { conteúdos editoriais }\end{array}$ & $\begin{array}{l}\text { PTI - process theory of } \\
\text { internationalization } \\
\text { INV - international new } \\
\text { venture }\end{array}$ & $\begin{array}{c}\text { Relação entre drivers } \\
\text { externos e } \\
\text { internos de } \\
\text { organizações de países } \\
\text { desenvolvidos em } \\
\text { países emergentes }\end{array}$ \\
\hline $\begin{array}{l}\text { Dib e } \\
\text { Rocha } \\
(2008)\end{array}$ & Brasil & $\begin{array}{l}\text { Verificar as diferenças } \\
\text { entre empresas de } \\
\text { internacionalização } \\
\text { precoce e empresas } \\
\text { que seguem o modelo } \\
\text { de internacionalização } \\
\text { gradual }\end{array}$ & $\begin{array}{l}\text { Survey por internet, } \\
\text { com empresas da } \\
\text { indústria brasileira de } \\
\text { software }\end{array}$ & Born Global & $\begin{array}{l}\text { Relação entre teoria } \\
\text { de born global e de } \\
\text { Uppsala }\end{array}$ \\
\hline $\begin{array}{l}\text { Dib e } \\
\text { Rocha } \\
(2009)\end{array}$ & Brasil & $\begin{array}{l}\text { Identificar as principais } \\
\text { características do processo } \\
\text { de internacionalização } \\
\text { born globals da industria } \\
\text { de software brasileira }\end{array}$ & $\begin{array}{l}\text { Survey, na indústria } \\
\text { brasileira de software, } \\
\text { foco em empresas de } \\
\text { desenvolvimento }\end{array}$ & Born Global & $\begin{array}{c}\text { Características } \\
\text { do processo de } \\
\text { internacionalização de } \\
\text { born globals }\end{array}$ \\
\hline Dib (2008) & Brasil & $\begin{array}{c}\text { Propor hipóteses sobre } \\
\text { operacionalização de born } \\
\text { globals }\end{array}$ & $\begin{array}{l}\text { Estudo bibliográfico na } \\
\text { literatura sobre o tema }\end{array}$ & Born Global & $\begin{array}{c}\text { Proposição de hipóteses } \\
\text { para operacionalização } \\
\text { do conceito de born } \\
\text { global }\end{array}$ \\
\hline $\begin{array}{l}\text { Kretschmer } \\
\quad \text { et al. } \\
(2018)\end{array}$ & Brasil & $\begin{array}{c}\text { Analisar os recursos } \\
\text { e as capacidades } \\
\text { organizacionais relevantes } \\
\text { para uma Born Global } \\
\text { brasileira e o papel } \\
\text { do desenvolvimento } \\
\text { das Capacidades } \\
\text { Dinâmicas na evolução } \\
\text { e competitividade da } \\
\text { empresa }\end{array}$ & $\begin{array}{c}\text { Estudo de caso } \\
\text { único, com coleta de } \\
\text { dados por entrevistas } \\
\text { semiestruturadas e } \\
\text { documentos internos e } \\
\text { externos, e análise de } \\
\text { conteúdo }\end{array}$ & $\begin{array}{c}\text { Born Global e } \\
\text { Capacidades Dinâmicas }\end{array}$ & $\begin{array}{l}\text { Os resultados sustentam } \\
\text { que o histórico de } \\
\text { atuação internacional } \\
\text { da empresa foi } \\
\text { estruturado por meio de } \\
\text { seus ativos e recursos } \\
\text { idiossincráticos } \\
\text { e capacidade de } \\
\text { se adaptar e de } \\
\text { se reconfigurar } \\
\text { constantemente } \\
\text { de acordo com as } \\
\text { mudanças e os novos } \\
\text { desafios competitivos. }\end{array}$ \\
\hline $\begin{array}{l}\text { Limp, } \\
\text { Rezende } \\
\text { e Versiani } \\
\text { (2016) }\end{array}$ & Brasil & $\begin{array}{c}\text { Compreender } \\
\text { até que ponto a } \\
\text { internacionalização da } \\
\text { empresa como um todo } \\
\text { pode ser explicada pela } \\
\text { interdependência em } \\
\text { suas distintas trajetórias } \\
\text { internacionais }\end{array}$ & $\begin{array}{l}\text { Qualitativo do tipo } \\
\text { estudo de caso em uma } \\
\text { empresa brasileira }\end{array}$ & $\begin{array}{c}\text { Modelos de } \\
\text { internacionalização }\end{array}$ & $\begin{array}{l}\text { Apresenta como as } \\
\text { empresas globais } \\
\text { nascidas conseguem } \\
\text { combinar expansões } \\
\text { simultaneamente }\end{array}$ \\
\hline
\end{tabular}




\begin{tabular}{|c|c|c|c|c|c|}
\hline $\begin{array}{l}\text { Ribeiro e } \\
\text { Pimentel } \\
(2009)\end{array}$ & Brasil & $\begin{array}{c}\text { Entender como a } \\
\text { localização em uma região } \\
\text { de concentração de EBT } \\
\text { influencia a } \\
\text { decisão e o processo } \\
\text { de internacionalização } \\
\text { de duas empresas de } \\
\text { tecnologia avançada }\end{array}$ & $\begin{array}{l}\text { Qualitativo, do tipo } \\
\text { estudo de caso, em duas } \\
\text { empresas de setores de } \\
\text { tecnologia avançada da } \\
\text { região de Campinas: } \\
\text { CI,T e Griaule } \\
\text { Biometrics }\end{array}$ & Born Global & $\begin{array}{c}\text { Relação entre } \\
\text { concentração de EBTs } \\
\text { e decisão e processo de } \\
\text { internacionalização }\end{array}$ \\
\hline $\begin{array}{l}\text { Rocha et } \\
\text { al. }(2015)\end{array}$ & Brasil & $\begin{array}{l}\text { Entender como a relação } \\
\text { entre o international } \\
\text { new venture e a rede de } \\
\text { corporação multinacional } \\
\text { começa e evolui. E em } \\
\text { que medida e em quais } \\
\text { circunstâncias essas } \\
\text { relações simbióticas } \\
\text { assimétricas são um modo } \\
\text { de entrada valioso nos } \\
\text { mercados internacionais } \\
\text { de serviços INVs }\end{array}$ & $\begin{array}{c}\text { Estudo de caso em } 4 \\
\text { empresas }\end{array}$ & $\begin{array}{c}\text { International new } \\
\text { venture e } \\
\text { Relacionamento } \\
\text { simbiótico assimétrico }\end{array}$ & $\begin{array}{l}\text { Apresentação da } \\
\text { importância da } \\
\text { rede de corporação } \\
\text { multinacional } \\
\text { para o processo de } \\
\text { internacionalização }\end{array}$ \\
\hline $\begin{array}{l}\text { Silva e Dib } \\
\text { (2011) }\end{array}$ & Brasil & $\begin{array}{c}\text { Estudar empresas } \\
\text { do setor de software } \\
\text { brasileiro com processos } \\
\text { de internacionalização } \\
\text { acelerados, buscando } \\
\text { verificar as principais } \\
\text { particularidades e a } \\
\text { comparação com o } \\
\text { referencial teórico } \\
\text { existente }\end{array}$ & $\begin{array}{c}\text { Estudo de caso } \\
\text { em } 4 \text { empresas de } \\
\text { desenvolvimento de } \\
\text { software }\end{array}$ & $\begin{array}{c}\text { Abordagens } \\
\text { Comportamentais e } \\
\text { Modelo de Uppsala } \\
\text { Born Global }\end{array}$ & $\begin{array}{l}\text { Comparação entre born } \\
\text { globals e referencial } \\
\text { teórico existente }\end{array}$ \\
\hline $\begin{array}{l}\text { Stocker } \\
\text { e Abib } \\
(2017)\end{array}$ & Brasil & $\begin{array}{l}\text { Analisar os fatores de } \\
\text { risco percebidos na } \\
\text { internacionalização das } \\
\text { empresas born globals de } \\
\text { origem brasileira. }\end{array}$ & $\begin{array}{l}\text { Adotou-se a pesquisa } \\
\text { de abordagem } \\
\text { qualitativa, com uso da } \\
\text { estratégia de estudos } \\
\text { de casos múltiplos, } \\
\text { e, para isso, foram } \\
\text { selecionadas sete } \\
\text { microcervejarias com } \\
\text { relevância e destaque } \\
\text { nacional. }\end{array}$ & $\begin{array}{c}\text { Internacionalização } \\
\text { e Negócios } \\
\text { internacionais. }\end{array}$ & $\begin{array}{l}\text { Os fatores risco } \\
\text { monetário e do risco- } \\
\text { país mais relevantes } \\
\text { e que geram maior } \\
\text { preocupação por parte } \\
\text { das empresas. }\end{array}$ \\
\hline $\begin{array}{l}\text { Stocker } \\
\text { e Abib } \\
(2017)\end{array}$ & Brasil & $\begin{array}{l}\text { Compreender o processo } \\
\text { de internacionalização em } \\
\text { born globals de origem } \\
\text { brasileira. }\end{array}$ & $\begin{array}{l}\text { Adotou-se a pesquisa } \\
\text { de abordagem } \\
\text { qualitativa, com } \\
\text { uso da estratégia } \\
\text { de estudo de casos } \\
\text { múltiplos, e, para isso, } \\
\text { foram selecionadas } 7 \\
\text { microcervejarias com } \\
\text { relevância e destaque } \\
\text { nacional. }\end{array}$ & $\begin{array}{l}\text { Internacionalização, } \\
\text { estratégias de } \\
\text { internacionalização e } \\
\text { negócios internacionais. }\end{array}$ & $\begin{array}{l}\text { Caracterizar } \\
\text { o processo de } \\
\text { internacionalização das } \\
\text { empresas, motivadas } \\
\text { pelo background } \\
\text { e experiência } \\
\text { internacional dos seus } \\
\text { fundadores. }\end{array}$ \\
\hline $\begin{array}{l}\text { Zonta e } \\
\text { Amal } \\
\text { (2017) }\end{array}$ & $\begin{array}{l}\text { África } \\
\text { do Sul, } \\
\text { Brasil e } \\
\text { China }\end{array}$ & $\begin{array}{l}\text { Compreender como as } \\
\text { instituições e as redes } \\
\text { afetam o crescimento } \\
\text { internacional das } \\
\text { empresas nascidas em } \\
\text { mercados emergentes }\end{array}$ & $\begin{array}{l}\text { Qualitativo do tipo } \\
\text { estudo de caso } \\
\text { múltiplo, com análise } \\
\text { baseada em proposição } \\
\text { teórica }\end{array}$ & Born Global & $\begin{array}{c}\text { Apresentação da } \\
\text { importância das redes } \\
\text { para o crescimento das } \\
\text { empresas Born Globals } \\
\text { de países emergentes }\end{array}$ \\
\hline
\end{tabular}

Fonte: Elaborado pelos autores com base nos artigos analisados.

Dos artigos analisados, 15 tratam de empresas brasileiras (CARVALHO; PAES, 2006; DIB, 2008; DIB; ROCHA, 2008, 2009; RIBEIRO; PIMENTEL, 2009; DIB; ROCHA, SILVA, 
2010; FERNANDES; ROCHA; SEIFERT JUNIOR, 2011; SILVA; DIB, 2011; RIBEIRO; OLIVEIRA JUNIOR; BORINI, 2012; ROCHA et al., 2015; LIMP; REZENDE; VERSIANI, 2016; ZONTA; AMAL, 2017; STOCKER; ABIB, 2017; KRETSCHMER et al., 2018), seis estudos referem-se ao processo de internacionalização de empresas chinesas, (ZHANG; TANSUHAJ; MCCULLOUGH, 2009; NAUDÉ; ROSSOUW, 2010; KHAVUL et al., 2010; WOOD et al., 2011; CLERCQ; ZHOU, 2014; ZONTA; AMAL, 2017), quatro de empresas indianas (KHAVUL et al., 2010; VARMA, 2010; WOOD et al, 2011; KUMAR, 2012), dois remetem a empresas africanas (WOOD et al., 2011; ZONTA; AMAL, 2017), e um analisa os fatores que influenciam a internacionalização em países emergentes, analisando a Rússia, entre outros (LAMOTTE; COLOVIC, 2015).

Observa-se, pois, escassez de estudos sobre o tema ora analisado, motivo pelo qual a compreensão da forma como o fenômeno das international new ventures é tratado nesses estudos é essencial para compreensão do arcabouço científico existente até então. Observa-se que há artigos que compreendem mais de um país que compõe os BRICS, a exemplo de Wood et al. (2011) que traz uma análise das born globals provenientes da China, Índia, África do Sul e México com exemplar rigor metodológico e processo de amostragem abrangente, permitindo comparações e análises transversais em relação a tais países.

Além disso, a prevalência de estudos sobre o Brasil não reflete a importância do país diante da produção acadêmica mundial, tendo em vista o viés produzido pela seleção de artigos publicados em revistas e anais de congressos nacionais, especificamente da ANPAD, o que resultou em um alto número de estudos sobre o Brasil, 14 no total.

Verifica-se, no caso dos artigos selecionados nos anais da ANPAD, perceptível endogeneidade na produção acadêmica nacional, em função de alguns autores com grande quantidade de estudos produzidos com mesma fundamentação teórica, mas diferente foco de pesquisa, o que revela a dinâmica da produção acadêmica no sentido de se adicionar por meio de cada uma das pequenas contribuições ao arcabouço do conhecimento científico sobre determinado fenômeno (DIB, 2008; DIB; ROCHA, 2008, 2009; RIBEIRO; PIMENTEL, 2009; DIB; ROCHA; SILVA, 2010; SILVA; DIB, 2011; RIBEIRO; OLIVEIRA JUNIOR; BORINI, 2012; ZONTA; AMAL, 2017; STOCKER; ABIB, 2017).

No que diz respeito aos periódicos científicos nos quais os estudos sobre as born globals foram publicados, o destaque foi para o Journal of International Entrepreneurship, com a publicação de quatro artigos (ZHANG; TANSUHAJ; MCCULLOUGH, 2009; NAUDÉ; ROSSOUW, 2010; DIB; ROCHA; SILVA, 2010; KUMAR, 2012). Os demais periódicos identificados tiveram cada um uma publicação, quais sejam: Journal of International Marketing (KHAVUL et al., 2010), Entrepreneurship Theory and Practice (FERNANDES; ROCHA; SEIFERT JUNIOR, 2011), Journal of Small Business Management (WOOD et al., 2011), Advanced Research in Management (VARMA, 2010), Revista de Administração Contemporânea (RIBEIRO; OLIVEIRA JUNIOR; BORINI, 2012)e M@n@gement (LAMOTTE; COLOVIC, 2015). A publicação em anais brasileiros foi concentrada em eventos organizados pela ANPAD e totalizaram 12 dos 23 artigos analisados (CARVALHO; PAES, 2006; DIB, 2008; DIB; ROCHA, 2008, 2009; RIBEIRO; PIMENTEL, 2009; SILVA; DIB, 2011; ROCHA et al., 2015; LIMP; REZENDE; VERSIANI, 2016; ZONTA; AMAL, 2017; STOCKER; ABIB, 2017; KRETSCHMER et al., 2018).

\section{ANÁlise DE CONTEÚdo DOS ARTIGOS}

A análise dos artigos identificados mediante os critérios para a seleção da produção científica sobre international new venture de países emergentes foi realizada por meio do levantamento de sete dimensões relevantes dos 
estudos: (i) autor(es); (ii) país(es); (iii) periódico; (iv) pergunta de pesquisa; (v) metodologia utilizada; (vi) abordagem teórica e; (vii) conclusões e/ou contribuições para o tema.

\subsection{PERGUNTAS DE PESQUISA}

Quanto às perguntas de pesquisa, a atualidade do tema aponta para a necessidade de compreensão holística do processo de internacionalização das empresas born globals (DIB; ROCHA, 2009; NAUDÉ; ROSSOUW, 2010; WOOD et al., 2011; SILVA; DIB, 2011; VARMA, 2010), bem como para a comparação de suas características e forma de atuação frente às empresas exportadoras tradicionais (DIB; ROCHA, 2008, 2009; ZHANG; TANSUHAJ; MCCULLOUGH, 2009; DIB; ROCHA; SILVA, 2010). Trata-se do processo de definição de um fenômeno por meio da sua comparação do que não é. No caso, a comparação das international new ventures com as empresas exportadoras tradicionais permite aos estudos referenciados identificar características distintivas (ou não) das global startups em relação às empresas internacionais tradicionais.

Outra similaridade existente entre alguns estudos corresponde à análise do fenômeno diante da influência de diversas dimensões, com o objetivo de identificar, para cada uma delas, particularidades das born globals que as diferenciam ou proporcionam vantagem competitiva em relação às demais empresas. Algumas das dimensões analisadas são drives internos e externos para internacionalização (CARVALHO; PAES, 2006; CLERCQ; ZHOU, 2014), capacidade empreendedora e performance (ZHANG; TANSUHAJ; MCCULLOUGH, 2009), região de concentração (RIBEIRO; PIMENTEL, 2009), capacidades dinâmicas (KHAVUL et al., 2010; KRETSCHMER et al., 2018), legitimação e decisão de internacionalização precoce (WOOD et al., 2011), variáveis da firma e empreendedoras (DIB; ROCHA; SILVA, 2010), fatores do ambiente externo da empresa no país de origem, fatores internos da organização e fatores ligados ao empreendedor
(RIBEIRO; OLIVEIRA JUNIOR; BORINI, 2012) e internacionalização precoce (LAMOTTE; COLOVIC, 2015).

Dimensões relativas à experiência internacional individual e/ou organizacional como fator relevante para internacionalização e aprendizado também foram abordados em alguns dos artigos identificados (DIB; ROCHA, 2008; RIBEIRO; PIMENTEL, 2009; ZHANG; TANSUHAJ; MCCULLOUGH, 2009; VARMA, 2010; DIB; ROCHA; SILVA, 2010; RIBEIRO; OLIVEIRA JUNIOR; BORINI, 2012; CLERCQ; ZHOU, 2014). Assim, com temas relacionados à inserção dessas empresas em redes como propulsores do processo de internacionalização, há as pesquisas de Carvalho e Paes (2006), Dib, Rocha e Silva (2010), Kumar (2012) e Silva e Dib (2011), com resultados similares e interessantes encontrados em estudos realizados no Brasil e na Índia, no sentido de que a inserção em redes não possui significância para o processo de internacionalização, de modo que essa dimensão pode ser comparada com estudos de países desenvolvidos como possível diferença entre born globals desses países e de países emergentes.

Ainda sobre a relação entre o international new venture e a rede de corporação multinacional, há dois estudos (ROCHA et al., 2015; ZONTA; AMAL, 2017) que colocam como essa relação começa e evolui e como as redes afetam o crescimento internacional de empresas nascidas em mercados emergentes, cujos resultados apontam que as redes são importantes propulsores para o crescimento dessas empresas.

Limp, Rezende e Versiani (2016) abordam sobre a internacionalização da empresa em várias trajetórias, buscando compreender como as empresas globais nascidas conseguem combinar expansões simultaneamente.

Os estudos de Stocker e Abib (2017) buscaram identificar os fatores de riscos percebidos na internacionalização de organizações born globals e compreender o processo de internacionalização de born globals de origem brasileira.

Conclui-se, pois, que os artigos sobre born globals de países emergentes que com- 
põem os BRICS ainda se concentram em identificar similaridades, fatores de riscos, processo de internacionalização e diferenças entre o fenômeno e as empresas internacionais tradicionais por meio do teste de inúmeras de suas dimensões, o que evidencia o estágio inicial de desenvolvimento da teoria sobre o fenômeno, à medida que estão sendo testadas inúmeras dimensões com vistas à definição do constructo.

Além disso, alguns estudos analisam fatores institucionais relacionados às características e à competitividade das born globals de países emergentes (KHAVUL et al., 2010), o que se alinha à retórica de Cuervo-Cazurra (2012) sobre a possibilidade de extensão da teoria sobre internacionalização - neste caso de international new ventures - levando-se em consideração as características desses países.

\subsection{METODOLOGIA}

No que diz respeito às metodologias, os artigos utilizam tanto estudos qualitativos (CARVALHO; PAES, 2006; DIB, 2008; RIBEIRO; PIMENTEL, 2009; FERNANDES; ROCHA; SEIFERT JUNIOR, 2011; SILVA; DIB, 2011; VARMA, 2010; KUMAR, 2012, LIMP; REZENDE; VERSIANI, 2016; ZONTA; AMAL, 2017; STOCKER; ABIB, 2017; KRETSCHMER et al., 2018) quanto estudos quantitativos (DIB; ROCHA, 2008; ZHANG; TANSUHAJ; MCCULLOUGH, 2009; DIB; ROCHA, 2009; NAUDÉ; ROSSOUW, 2010; KHAVUL et al., 2010; WOOD et al., 2011; DIB; ROCHA; SILVA, 2010; RIBEIRO; OLIVEIRA JUNIOR; BORINI, 2012). O equilíbrio de pesquisas quantitativas e quantitativas, no caso em questão, não se alinha à maturidade da teoria do fenômeno das born globals de países emergentes, pois, como mencionado, foram identificados somente quinze artigos sobre o tema na última década.

Confabula-se, pois, a utilização da teoria sobre born globals já consolidada pela teoria em relação a empresas provenientes de países desenvolvidos como arcabouço para a estruturação de frameworks dessas empresas em países emergentes e, a partir desse ponto, a busca pela generalização quanto ao entendimento do processo de internacionalização das firmas em análise, na busca por similaridades que expliquem o fenômeno.

Por outro lado, foram identificadas particularidades do fenômeno em países emergente que também podem ser importantes para apontar possíveis aspectos presentes somente nesses países que influenciam na internacionalização precoce de suas empresas, possibilitando na perspectiva retórica de Cuervo-Cazzura (2012) contribuir para a extensão da teoria existente sobre o tema.

Uma das dimensões que pode ser esclarecida quando analisada sob o ponto de vista das condições macro de Ghemawat (2001) - social, político-regulatório, geográfico e econômico refere-se ao setor dos quais as born globals dos países emergentes se originam. Mesmo consistindo em uma limitação para análise comparativa dos artigos, dada as particularidades e dinâmicas de cada setor, as international new ventures de países emergentes provêm de inúmeras áreas, a exemplo das empresas de manufatura exportadoras na China (ZHANG; TANSUHAJ; MCCULLOUGH, 2009), empresas de tecnologia da Índia (VARMA, 2010; KUMAR, 2012) e empresas de software Brasileiras (DIB; ROCHA, 2008; DIB; ROCHA, 2009; RIBEIRO; PIMENTEL, 2009; DIB; ROCHA; SILVA, 2010; SILVA; DIB, 2011; RIBEIRO; OLIVEIRA JUNIOR; BORINI, 2012), microcervejarias com relevância e destaque nacional (STOCKER; ABIB, 2017) e empresa de confecção feminina (KRETSCHMER et al., 2018), que, não necessariamente, possuem as mesmas características propulsoras para internacionalização que as empresas emblematicamente de alta tecnologia de economias desenvolvidas.

\subsection{ABORDAGEM TEÓRICA}

A abordagem teórica que prevalece nos artigos analisados é a Visão Baseada em Recursos (VBR) (ZHANG; TANSUHAJ; MCCULLOUGH, 2009; NAUDÉ; ROSSOUW, 
2010; VARMA, 2010; FERNANDES; ROCHA; SEIFERT JUNIOR, 2011; WOOD et al., 2011; KUMAR, 2012); no entanto, é possível visualizar bases teóricas sustentadas também pela abordagem institucional (VARMA, 2010; WOOD et al., 2011).

O destaque dos estudos embasados na VBR vai ao encontro do que afirmam Khight e Cavusgil (2004), de que a teoria, em um contexto de cultura para inovação, o qual permeia os ambientes em que o fenômeno ocorre, contribui para o entendimento de como conhecimento e capacidades organizacionais são desenvolvidos pelas firmas empreendedoras, refletindo as competências que levam essas empresas a se internacionalizarem.

O imperativo institucional enfatizado nos estudos de Varma (2010) e Wood et al. (2011) aponta para a necessidade de olhar para a dinâmica da relação entre a organização e o ambiente, de modo a apontar a existência de todo um arranjo institucional que permite a entrada precoce da firma no mercado.

Neste contexto, notam-se aspectos de empreendedorismo internacional levantados como fatores relevantes para o entendimento do fenômeno (DIB; ROCHA, 2008; ZHANG; TANSUHAJ; MCCULLOUGH, 2009; RIBEIRO; PIMENTEL, 2009; NAUDÉ; ROSSOUW, 2010; SILVA; DIB, 2011). Os autores, em sua maioria, destacam a importância da experiência internacional da organização e, especialmente, do perfil empreendedor dos gestores.

Por fim, no que tange às teorias específicas de firmas que se internacionalizam mais cedo, os estudos mesclaram international new ventures (CARVALHO; PAES, 2006; KHAVUL et al., 2010; LAMOTTE; COLOVIC, 2015; ROCHA et al., 2015) e born globals (DIB, 2008; DIB; ROCHA, 2008, 2009; RIBEIRO; PIMENTEL, 2009; DIB; ROCHA; SILVA, 2010; RIBEIRO; OLIVEIRA JUNIOR; BORINI, 2012; LAMOTTE; COLOVIC, 2015).

\subsection{ANÁLISE GERAL}

Os artigos analisados e que abordam as diferenças entre empresas tradicionais e born globals não apontam diferenças significativas entre esses dois tipos de firmas (ZHANG; TANSUHAJ; MCCULLOUGH, 2009; DIB; ROCHA, 2009; DIB; ROCHA; SILVA, 2010), reafirmando a ideia conceitual de born global apresentada por Ovaitt e McDougall (1994) no início do presente artigo, em que os autores destacam o compromisso e a intenção estratégica das empresas em se internacionalizarem precocemente.

Com base na literatura existente sobre o tema, alguns artigos buscaram uma comparação com firmas born globals de países emergentes (CARVALHO; PAES, 2006) e com firmas born globals de setores específicos (SILVA; DIB, 2011), à procura de particularidades que pudessem contribuir para a unidade de análise em questão.

Com relação aos artigos que buscam um comparativo entre firmas born globals e firmas que se internacionalizam gradualmente, seguindo o modelo da escola Nórdica (DIB; ROCHA, 2008), ou tardiamente (ou sem intenção) (WOOD et al., 2011), foi possível notar nesta primeira que, no caso de empresas brasileiras de software internacionalizadas, as born globals, além de maior velocidade de internacionalização, possuem, também, maior parcela do seu faturamento de atividades internacionais, bem como maior capacidade de inovação, maior orientação ao cliente e maior conhecimento técnico ou científico (empreendedor ou grupo de empreendedores); no entanto, são mais sensíveis ao risco. Com relação ao estudo de Wood et al. (2011), nota-se que empresas que se internacionalizam cedo são responsáveis por mais da metade da variância explicada na intensidade de vendas internacionais, mediando os efeitos do conhecimento gerencial e a orientação do mercado sobre essa intensidade.

Hipóteses de pesquisa, escalas de análise e modelos que buscassem explicar o fenômeno também são foco de estudos de alguns artigos que, vivenciando a realidade do país, procuraram contribuir para um maior entendimento do tema: hipóteses sobre características de born globals brasileiras (DIB, 2008); escala de ca- 
pacidade de empreendedorismo internacional para estudos empíricos sobre a área (ZHANG; TANSUHAJ; MCCULLOUGH; 2009); modelo integrativo sobre firmas e variáveis empreendedoras (DIB; ROCHA; SILVA; 2010); hipóteses sobre postura estratégica empresarial e esforço de aprendizagem internacional (CLERCQ; ZHOU, 2014); hipóteses sobre o meio ambiente, indústria e fatores relacionados à empresa que melhoram ou restringem a rápida internacionalização de novas empresas de países emergentes (LAMOTTE; COLOVIC, 2015).

Por fim, a análise destaca as pesquisas que tentam relacionar internacionalização de firmas born globals com diferentes variáveis de análise: influência da localização na decisão e no processo de internacionalização (RIBEIRO; PIMENTEL, 2009), determinantes da internacionalização precoce (NAUDÉ; ROSSOUW, 2010; LAMOTTE; COLOVIC, 2015), posicionamento de novos produtos (FERNANDES; ROCHA; SEIFERT JUNIOR, 2011), aproveitamento de oportunidades por meio de recursos (KUMAR, 2012), influência de fatores do ambiente externo da empresa no país de origem, fatores internos da organização e fatores ligados ao empreendedor (RIBEIRO; OLIVEIRA JUNIOR; BORINI, 2012).

\section{CONCLUSÃO}

Em face do mapeamento ora realizado, que teve como objetivo analisar a produção científica existente sobre international new ventures, born globals e global startups originárias de países emergentes com enfoque nos países que compõem os BRICS (Brasil, Rússia, Índia, China e África do Sul), pode-se afirmar que a produção acadêmica sobre o tema ainda é escassa e tem como principal característica a compreensão holística do processo de internacionalização dessas empresas; muitas vezes, operacionalizado por meio da comparação das global startups com empresas internacionais tradicionais (DIB; ROCHA, 2008, 2009; ZHANG; TANSUHAJ; MCCULLOUGH, 2009; DIB; ROCHA; SILVA, 2010).
Busca-se, nesse sentido, definir com precisão o fenômeno e identificar características distintivas (ou não) das global startups em relação a tais empresas. Além disso, fica claro o objetivo de alguns estudos em explorar a influência de diversas dimensões relacionadas ao processo de internacionalização dessas empresas para identificar particularidades das born globals que as diferenciam ou proporcionam vantagem competitiva (CARVALHO; PAES, 2006; DIB; ROCHA; SILVA, 2010; KHAVUL et al., 2010; RIBEIRO; PIMENTEL, 2009; ZHANG; TANSUHAJ; MCCULLOUGH, 2009).

Em grande parte dos casos, a Visão Baseada em Recursos é o fundamento teórico utilizado para a compreensão do fenômeno (ZHANG; TANSUHAJ;MCCULLOUGH, 2009; NAUDÉ; ROSSOUW, 2010; VARMA, 2010; FERNANDES; ROCHA; SEIFERT JUNIOR, 2011; WOOD et al., 2011; KUMAR, 2012), mas em outros, a literatura de referência utiliza-se de princípios da teoria institucional para complementar e fundamentar a análise pretendida (VARMA, 2010; WOOD et al., 2011). Metodologicamente, a existência de estudos quantitativos e qualitativos evidencia o amadurecimento da pesquisa sobre born globals de forma genérica, mas as particularidades institucionais dos países emergentes ainda são pouco exploradas e levadas em consideração.

Os resultados obtidos com a produção científica em análise pavimentam o caminho trilhado até então na consolidação do arcabouço de conhecimento sobre as international new ventures provenientes de países emergentes e deixam clara a necessidade de se identificar elementos distintivos em relação às born globals de países desenvolvidos com foco na extensão da teoria sobre o fenômeno mundial das born globals.

\subsection{AGENDA DE PESQUISA}

Cientes das limitações metodológicas deste mapeamento e do viés em relação aos artigos brasileiros, a agenda de pesquisa que se propõe é direcionada à comparação exaustiva 
das inúmeras dimensões já pesquisadas sobre born globals de países desenvolvidos em relação às born globals de países emergentes, com o intuito de se identificar características distintivas que o ambiente de negócios - países emergentes e BRICS - pode gerar nessas empresas. Capitalizar sobre os insights de Curevo-Cazurra (2012) é de extrema importância para que a navegação em mar tão tormentoso possa ser feita de forma mais produtiva e eficiente, comunicando-se com o estado da arte da produção científica na área para possível contribuição em contexto específico das international new ventures. Outra sugestão de pesquisa estaria relacionada à ampliação do levantamento para outras bases de dados, como a Web of Science.

Não obstante, as poucas pesquisas sobre a Rússia e a África do Sul fazem surgir a necessidade de comunicação com pesquisadores e instituições desses países com vistas ao estabelecimento de cooperação para estruturação de base de dados e produção científica sobre eles. A maior inserção da China, Índia e Brasil, na lógica de produtividade acadêmica mundial, facilita eventual pesquisa transversal sobre os BRICS, mas, como pode ser observado, somente o artigo de Wood et al. (2011) logrou tão almejada transversalidade.

Outro aspecto importante refere-se à análise de pesquisas realizadas sobre países emergentes que não compõem os BRICS, tendo em vista a representatividade política e econômica desses países no contexto mundial e eventual contribuição para a compreensão do fenômeno e extensão da teoria sobre as born globals de países emergentes. A pesquisa de Wood et al. (2011), por exemplo, analisou o fenômeno no México, mas deixou de fora o Brasil, motivo pelo qual a análise detalhada do artigo poderá responder à pergunta sobre a relevância e contribuição desse país para a discussão que ora se propõe.

Por fim, pode-se a afirmar que a pesquisa sobre international new ventures de países emergentes ainda é incipiente, e há muito trabalho a ser feito para que se possa afirmar que as condições macro relacionadas aos países de origem (GHEMAWAT, 2001) trarão contribui- ção efetiva para a extensão da teoria sobre born globals existentes até então, conforme preconizado por Cuervo-Cazurra (2012).

\section{REFERÊNCIAS}

ARDICHVILI, A.; GASPARISHVILI, A. Russian and Georgian entrepreneurs and non entrepreneurs: A study of value differences. Organization Studies, v. 24, n. 1, p. 29-46, 2003.

CARVALHO, S.; PAES, L. R. A. Drivers da Internacionalização de Born Globals: Estudo de uma Empresa de Syndication. In: ENCONTRO DA ANPAD, 30., 2006, Salvador. Anais [...]. Salvador: Anpad: 2006. Disponível em: http:// www.anpad.org.br. Acesso em: 20 maio 2013.

CLERCQ, D.; ZHOU, L. Entrepreneurial strategic posture and performance in foreing markets: the critical role of international learning effort. Journal of International Marketing, v. 22, n. 2, p. 47-67, 2014.

CRESWELL, J. W. W. Projeto de pesquisa: métodos qualitativo, quantitativo e misto. 2. ed. Porto Alegre: Bookman, 2010.

CUERVO-CAZURRA, A. Extending theory by analyzing developing country multinational companies: Solving the Goldilocks debate. Global Strategy Journal, v. 2, p. 153-167, 2012.

DIB, A. L. Caracterizando o Processo de Internacionalização Born Global: Discussão sobre a Conceituação Empírica do Fenômeno e Hipóteses de Pesquisa. In: ENCONTRO DA ANPAD, 32., 2008, Rio de Janeiro. Anais [...]. Rio de Janeiro: Anpad, 2008. Disponível em: http://www.anpad.org.br. Acesso em: 20 maio 2013.

DIB, A. L.; ROCHA, A. Internacionalização Precoce versus Internacionalização Gradual: um Estudo sobre Born Globals na Indústria. Brasileira de Software. In: ENCONTRO DA 
ANPAD, 32., 2008, Rio de Janeiro. Anais [...]. Rio de Janeiro: Anpad, 2008. Disponível em: http://www.anpad.org.br. Acesso em: 20 maio 2013.

DIB, L. A.; ROCHA, A. Caracterizando o Processo de Internacionalização Born Global: Pesquisa Quantitativa na Indústria Brasileira de Software. 2009. Disponível em http:// www.anpad.org.br. Acesso em: 20 maio 2013.

DIB, L.; ROCHA, A.; SILVA, J. The internationalization process of Brazilian software firms and the born global phenomenon: Examining firm, network, and entrepreneur variables. Journal of International Entrepreneurship, v. 8, n. 3, p. 233-253, 2010.

EVANS, D.; PEARSON, A. Systematic reviews: gatekeepers of nursing knowledge. Journal of Clinical Nursing, Oxford, v. 10, n. 5, p. 593-599, 2001.

FERNANDES, B. H. R.; ROCHA, A.; SEIFERT JUNIOR, R. Trikke Tech Inc. Entrepreneurship Theory and Practice, v. 36, n. 5, p. 1075-1099, 2011.

GHEMAWAT, P. Distance still matters: the hard reality of global expansion. Harvard Business Review, v. 79, n 8, p. 137-147, 2001.

JOHANSON, J.; VAHLNE, J. E. The mechanism of internationalization. International Marketing Review, v. 7, n. 4, p. 11-24, 1990.

KHAVUL, S. et al. Going global with innovations from emerging economies: investment in customer support capabilities pays off. Journal of International Marketing, v. 18, n. 4, p. 2242, 2010.

KNIGHT, G. A.; CAVUSGIL, S. T. Innovation, organizational capabilities, and the born-global firm. Journal of International Business Studies, v. 35, p. 124-141, 2004.
KNIGHT, G. A.; LIESCH, P. W. Internationalization: From incremental to born global. Journal of World Business, v. 51, n. 1, p. 93-102, 2016.

KRETSCHMER, C. et al. O papel das capacidades dinâmicas na evolução e competitividade das born global. In: ENCONTRO DA ANPAD, 42., 2018, Curitiba. Anais [...]. Curitiba: Anpad, 2018. Disponível em: http://www. anpad.org.br. Acesso em: 7 dez. 2020.

KUMAR, N. The resource dynamics of early internationalising Indian IT firms. Journal of International Entrepreneurship, v. 10, n. 3, 2012.

LAMOTTE, O.; COLOVIC, A. Early internationalization of new ventures from emerging countries: the case of transition economies. M@n@gement, v. 18, n. 1, p. 8-30, 2015.

LIMP, A.; REZENDE, S. F. L.; VERSIANI, A. Interdependence across a firm's international trajectories. RAC, v. 20, n. 5, p. 590-609, 2016.

MADSEN, T. K.; SERVAIS, P. The internationalization of born globals: An evolutionary process? International Business Review, v. 6, n. 6, p. 561-583, 1997.

MARCONI, M. D. A.; LAKATOS, E. M. Fundamentos de metodologia científica. 7 . ed. São Paulo: Atlas, 2010.

MCDOUGALL, P. P.; OVIATT, B. M.; SHRADER, R. C. A comparison of international and domestic new ventures. Journal of International Entrepreneurship, v. 1, n. 1, p. 59-82, 2003.

MENDES, A. L. L.; FRACOLLI, L. A. Revisão sistemática de literatura e metassíntese qualitativa: considerações sobre sua aplicação na pesquisa em enfermagem. Texto Contexto Enfermagem, Florianópolis, v. 17, n. 4, p. 771779, out./dez. 2008. 
NAUDÉ, W.; ROSSOUW, S. Early international entrepreneurship in China: Extent and determinants. Journal of International Entrepreneurship, v. 8, n. 1, p. 87-111, 2010.

OVIATT, B. M.; MCDOUGALL, P. P. Toward a Theory of International New Ventures. Journal of International Business Studies, v. 25, n. 1, p. 45-64, 1994.

PAUL, J.; ROSADO-SERRANO, A. Gradual internationalization vs. born-global/international new venture models: A review and research agenda. International Marketing Review, v. 36, n. 6, p. 830-858, 2019.

RIBEIRO, F. C. F.; PIMENTEL, J. E. A. Empresas Born Globals Brasileiras: a Influência do Perfil do Empreendedor e da Localização Geográfica. In: ENCONTRO DA ANPAD, 33., 2009, São Paulo. Anais [...]. São Paulo: Anpad, 2009. Disponível em: http://www.anpad.org.br. Acesso em: 20 maio 2013.

RIBEIRO, F. R.; OLIVEIRA JUNIOR.; BORINI, F. Internacionalização Acelerada de Empresas de Base Tecnológica: o Caso das Born Globals Brasileiras. RAC - Revista de Administração Contemporânea, v. 16, n. 6, p. 866888, 2012.

ROCHA, A. M. C. et al. Building asymmetric symbiotic relationships: international new ventures and the multionational network. In: ENCONTRO DA ANPAD, 39., 2015, Belo Horizonte. Anais [...]. Belo Horizonte: Anpad, 2015. Disponível em: http://www.anpad.org.br. Acesso em: 1 nov. 2017.

SILVA, R. S. M.; DIB, L. A. Processos de Internacionalização de Born Globals: Estudo de Casos de Empresas Brasileiras de Software. 2011. Disponível em: http://www.anpad.org.br. Acesso em: 20 maio 2013.

STOCKER, F.; ABIB, G. Internacionalização de born globals: análise do contexto das cer- vejarias artesanais brasileiras. 2017. Disponível em: http://www.anpad.org.br. Acesso em: 15 dez. 2017.

STOCKER, F.; ABIB, G. Risco em born globals: análise da internacionalização de cervejarias artesanais brasileiras. 2017. Disponível em: http://www.anpad.org.br. Acesso em: 15 dez. 2017.

THOMAS, A. S.; MUELLER, S. L. A case for comparative entrepreneurship: assessing the relevance of culture. Journal of International Business Studies, v. 31, n. 2, p. 287-301, 2000.

VARMA, S. The Global Startups from Indian IT - A Case Study. Journal of Advanced Research in Management, v. 1, n. 1, p. 45-55, 2010.

VIJAYAKUMAR, N.; SRIDHARAN, P.; RAO, K.Ch.S. Determinants of FDI in BRICS Countries: A Panel Analysis. International Journal of Business Science and Applied Management, v. 5, n. 3, p. 1-13, 2010.

WOOD, E. et al. Strategic Commitment and Timing of Internationalization from Emerging Markets: Evidence from China, India, Mexico, and South Africa. Journal of Small Business Management, v. 49, p. 252-282, 2011.

ZHANG, M.; TANSUHAJ, P.; MCCULLOUGH, J. International entrepreneurial capability: The measurement and a comparison between born global firms and traditional exporters in China. Journal of International Entrepreneurship, v. 7, n. 4, p.292-322, 2009.

ZONTA, T. C.; AMAL, M. Institutions, networks and the international growth of born globals from emerging markets. In: ENCONTRO DA ANPAD, 2017, Belo Horizonte. Anais [...]. Belo Horizonte: Anpad, 2017. http://www. anpad.org.br. Acesso em: 1 nov. 2017. 